\title{
Ophthalmological findings in elite amateur Turkish boxers
}

\author{
M Hazar, M Beyleroglu, M Subasi, M Or
}

Br J Sports Med 2002;36:428-430

See end of article for authors' affiliations

......................

Correspondence to:

Dr Or, Mesnevi sokak,

Burak apt, No:46/20,

06690 A Ayranci, Ankara,

Turkey;

meralor@superonline.com;

http://meralor.i.am

Accepted 19 September 2002
Objective: To evaluate the nature and incidence of pathological ocular conditions in boxing.

Methods: A group of 20 active, elite, amateur, asymptomatic Turkish boxers were examined and compared with a control group composed of 20 age matched sportsmen who were not boxers. The boxers had been actively boxing for 5-20 years (mean 9.65), were aged 16-34 (mean 22.25), and weighed $51-91 \mathrm{~kg}$ (mean 73.07). They had been involved in 67-500 fights (mean 143.8), with 5-40 losses (mean 17.75). All were championship title holders at the national, European, Olympic, or World level.

Results: An atrophic retinal hole was found in one boxer, which was treated with laser prophylaxis. In this series, the incidence of traumatic eye injuries was much lower than in the literature. Possible reasons are their young age, their division being mainly lightweight or middleweight, few fight losses, being elite boxers, their fighting distance being near or distant, protective methods, and racial factors. Conclusion: Boxing does not appear to be as hazardous to the eyes as previously reported, but prospective, longitudinal studies need to be carried out, including boxers of all divisions, ages, boxing experience, and level, and using various methods of fighting and protection. It should be made mandatory for all boxers to have a complete ophthalmological examination at the beginning of their careers and periodically thereafter.
B oxing is a sport with a long tradition, with roots going back thousands of years to the Olympics of the ancient Greeks. It is the only amateur or professional sport in which winning is linked to intentionally inflicting physical damage to the opponent. In recent years, we have become aware of its long term damage to health, especially chronic neurological, cerebral, and ophthalmological damage, documented by electroencephalographic recordings, computed tomograms, and neurological examination. ${ }^{12}$

Ocular injuries from boxing have been noted in the sports medicine and ophthalmic literature, but they are scarce with varying conclusions. Doggart ${ }^{3}$, in 1955, suggested that, ruptures of Descemet's membrane, hyphaema, glaucoma, iridodialysis, cataracts, retinal detachments, vitreous haemorrhage, maculopathies, and choroidal ruptures were potential ocular complications of boxing, but reported no data. Other reports followed this. The results varied widely between studies because neither the boxers chosen nor the examination methods were standardised. Although many studies have been reported, a well designed, prospective, cross sectional, or longitudinal study is needed describing the nature and severity of ocular damage from boxing and its visual consequences. ${ }^{4-6}$

In this study, we aimed to investigate ophthalmological findings in active, asymptomatic, elite, amateur boxers who hold national or international titles.

\section{MATERIALS AND METHODS}

A group of 20 active, elite, amateur, asymptomatic Turkish boxers were examined and compared with a control group composed of 20 age matched sportsmen who were not boxers. A thorough ophthalmological examination was performed including visual acuity, anterior segment examination, intraocular pressure, and retinal examination with a dilated pupil. At the time of examination, all boxers were active, having fought at least once in the preceding two weeks and trained by sparring five days a week. The number and length of rounds in a fight and the type of protective headgear and gloves were determined.

An extensive boxing and self medical history was obtained for each subject including age, weight division, years of boxing, mean number of fights, dominant arm, approximate number of sparring rounds and losses, and head and eye injuries in and out of the ring. They were also asked about previous ocular disease, eye diseases in the family, general health, and medication including anabolic steroids.

All boxers were visually asymptomatic when examined. They had been actively boxing for 5-20 years (mean 9.65 years), were aged 16-34 (mean 22.25), and weighed 51-91 kg (mean 73.07). They had been involved in 67-500 fights (mean 143.8), with 5-40 losses (mean 17.75). Their weight divisions were as follows: 51,54 , or $57 \mathrm{~kg}$ (five boxers); $60 \mathrm{~kg}$ (two); 63.5 or $71 \mathrm{~kg}$ (three); $75 \mathrm{~kg}$ (two); $81 \mathrm{~kg}$ (three); 91 or 9l $+\mathrm{kg}$ (five). All boxers were championship title holders at the national, European, Olympic, or World level.

Four boxers led with their right hands. Five boxers were near, 10 were distant, and five were middle distance fighters. Fights were composed of four rounds lasting two minutes each. The approximate number of trauma involving the eyes was about 45.4 to each eye. They all used headgear in their bouts and sparring rounds to protect their head and eyes. Two boxers complained of serious eye trauma in a fight. Others were not aware of any ocular or periocular trauma.

\section{RESULTS}

Of the 20 boxers examined, only one had any visual complaints; he had refractive disorders and his vision was 20/20 with myopic astigmate correction. There was a pigmented scar in the traumatised eye of one boxer. All the boxers in this series had 20/20 vision, no angle recession, no glaucoma, and no retinal detachment. There was an atrophic retinal hole in one eye of one boxer, which was treated with argon laser (figs 1 and 2). Three boxers who did not report any eye trauma had non-specific pigmentation in one of their eyes. 


\begin{tabular}{|c|c|c|c|c|c|c|c|c|}
\hline Number & $\begin{array}{l}\text { Age } \\
\text { (years) }\end{array}$ & $\begin{array}{l}\text { Division } \\
(\mathrm{kg})\end{array}$ & $\begin{array}{l}\text { Boxing } \\
\text { experience } \\
\text { (years) }\end{array}$ & $\begin{array}{l}\text { No of } \\
\text { bouts }\end{array}$ & $\begin{array}{l}\text { No of } \\
\text { losses }\end{array}$ & $\begin{array}{l}\text { Fighting } \\
\text { distance }\end{array}$ & $\begin{array}{l}\text { No of eye } \\
\text { trauma in } \\
\text { a bout } \\
\text { (approx) }\end{array}$ & Level \\
\hline 1 & 23 & 57 & 11 & 114 & 22 & Near & 17 & Gold medal (Turkey) \\
\hline 2 & 20 & 51 & 8 & 98 & 5 & Near & 13 & Gold medal (Turkey) \\
\hline 3 & 19 & 60 & 9 & 91 & 6 & Distant & 20 & Gold medal (Turkey) \\
\hline 4 & 16 & 57 & 5 & 67 & 7 & Distant & 10 & Gold medal (Turkey) \\
\hline 5 & 18 & 60 & 9 & 114 & 15 & Near & 15 & Gold medal (Turkey), World Championship, bronze medal \\
\hline 6 & 23 & 71 & 11 & 138 & 27 & Middle & 22 & Junior World Championship, silver medal \\
\hline 7 & 21 & 54 & 11 & 133 & 10 & Middle & 22 & Gold medal (Europe) \\
\hline 8 & 20 & 63.5 & 7 & 88 & 8 & Distant & 15 & Gold medal (Turkey) \\
\hline 9 & 18 & 71 & 7 & 120 & 30 & Distant & 12 & European and World championship, bronze medal \\
\hline 10 & 18 & 75 & 7 & 76 & 9 & Distant & 16 & Gold medal (Turkey) \\
\hline 11 & 31 & 81 & 20 & 500 & 40 & Distant & 8 & $\begin{array}{l}\text { Gold medal (World championship), Olympic games silver } \\
\text { medal }\end{array}$ \\
\hline 12 & 32 & 91 & 15 & 185 & 25 & Near & 15 & Gold medal (Turkey) \\
\hline 13 & 19 & 81 & 5 & 68 & 8 & Distant & 12 & Ankara region gold medal \\
\hline 14 & 17 & 57 & 5 & 63 & 6 & Distant & 10 & Ankara region gold medal \\
\hline 15 & 18 & 81 & 6 & 73 & 18 & Middle & 25 & Ankara region gold medal \\
\hline 16 & 20 & 75 & 7 & 75 & 16 & Distant & 13 & Gold medal (Turkey) \\
\hline 17 & 18 & 57 & 6 & 63 & 21 & Distant & 12 & Ankara region gold medal \\
\hline 18 & 32 & 71 & 18 & 450 & 25 & Middle & 23 & $\begin{array}{l}\text { Ankara region gold medal, Turkish championship bronze } \\
\text { medal }\end{array}$ \\
\hline 19 & 28 & 91 & 10 & 110 & 23 & Near & 12 & Gold medal (Turkey) \\
\hline 20 & 34 & 57 & 15 & 250 & 34 & Middle & 20 & Gold medal (Turkey) \\
\hline Mean & 22.25 & 73.07 & 9.65 & 143.8 & 17.75 & & 15.6 & \\
\hline
\end{tabular}

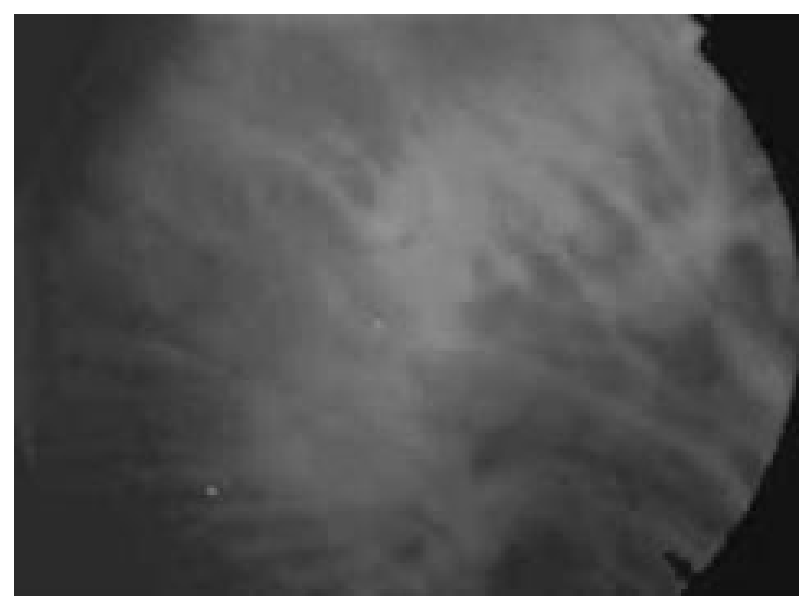

Figure 1 Atrophic retinal hole.

In the control group of 20 cases, two had simple myopia less than 1 dioptres, and in two cases peripheral snail tract degeneration was found.

\section{DISCUSSION}

In a boxing bout, the predisposition of the eye to trauma is determined by the distance of the fight, the power and placement of the fist, and protective equipment. The effect of trauma on the eye is related to the force, placement, velocity, number, and protective measures. Three mechanisms have been described to explain ocular changes associated with blunt trauma: coup injury, contrecoup injury, and equatorial expansion. ${ }^{7}$ Coup injury is the result of a direct blow producing local injury, and lesions of the lids and cornea, scleral, ciliary body, and peripheral retinal injuries are the result. Contrecoup injuries are found away from the area of impact but along a direct line of force traversing the globe. Subcapsular cataracts and traumatic maculopathy are results of this kind of trauma. The third mechanism is equatorial expansion which reduces the anterior-posterior equator of the globe, resulting

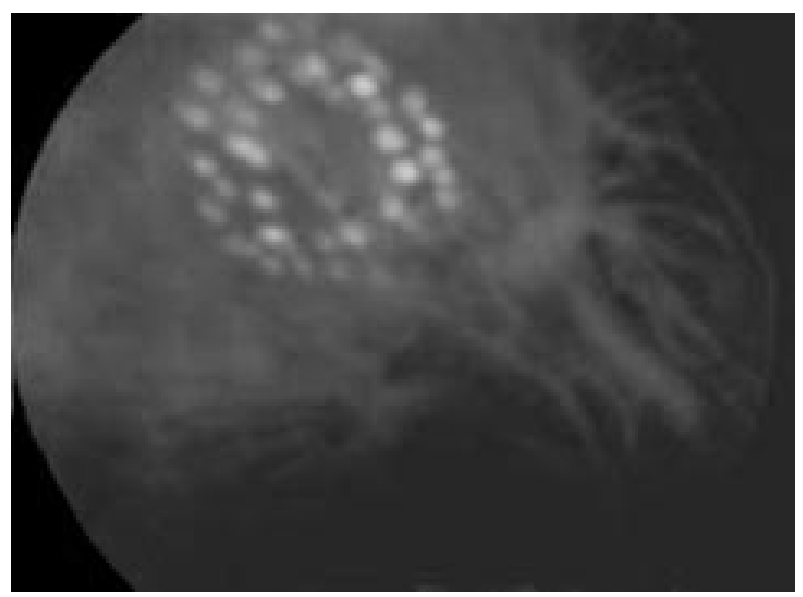

Figure 2 Retinal hole after laser treatment.

in distension of the equatorial sclera. The underlying retina and pars plana are separated from the vitreous base, resulting in vitreous detachment and tearing of the retina and pars plana. ${ }^{8}$ The incidence of retinal detachment caused by trauma varies between racial groups. The area that is the most susceptible to trauma is the inferior temporal area. Boxers use headgear in their bouts and sparring rounds. These air filled protectors have been found to protect the head in $70-80 \%$ cases of trauma, but cannot provide complete protection of the eye and head. Therefore trauma to the eyes, nose, maxilla, eyebrows, and mandibula are often encountered.

Wedrich et al ${ }^{9}$ reported a $16 \%$ incidence of angle recession in 25 asymptomatic boxers with a mean age of 23.5. The incidence of glaucoma related to angle recession is reported to be $7-9 \%$ and can even be manifest after 10 years. ${ }^{10}$ In this same series, lenticular opacities were seen in $16 \%$ of cases, and the incidence of posterior segment pathological conditions was $72 \%$. Traumatic retinal pigmentation was found in $60 \%$ of cases and retinal tears in $24 \%$. In our series, the rate of pathological eye conditions is quite low compared with other 
reports. Retinal pigmentation was the most common pathological condition seen (four $(20 \%)$ of the cases); only one of these boxers reported a serious eye trauma in a fight. An atrophic retinal hole was encountered in one case, which was not due to vitreoretinal traction.

Giovinazzo et $\mathrm{l}^{11}$ reported the ophthalmological findings on 74 boxers with a mean age of 25 . Angle abnormalities were encountered in 19\% and cataract also in 19\% of cases. Vision threatening injuries were found in $58 \%$ of patients. Macular pigment epithelial alterations and retinal tears were also encountered in up to $25 \%$ of cases. They concluded that the retinal tears were directly related to the total number of bouts and number of fights lost. The risk of retinal tears increased after six fights and two losses, and nearly all boxers who had had more than 100 fights had retinal tears. The rate of retinal detachment was much lower than the number of tears, and the authors explained this by the fact that their series mainly comprised young black boxers $(60 \%)$.

Vadala et $a l^{12}$ reported some asymptomatic traumatic changes in 75 experienced and novice boxers, and retinal detachment was seen in four cases, three as the result of trauma.

In another study, ocular injuries occurred in 5\% of boxers, and resulted in a longer hospital stay and disability than all other boxing injuries. ${ }^{13}$

The medical advisory board of the New York State and California Athletic Commission recommends that no boxer with a retinal detachment should be permitted to obtain a licence to box. The Medical Council of Australia has recommended that retinal detachments are a contraindication to a boxing career. $^{14}$

In our series, although boxers had a significantly greater risk of eye trauma than non-boxers, except for one atrophic retinal hole, no vision threatening pathologies such as cataract, angle recession, glaucoma, traumatic retinal tears, or retinal detachment existed. There are several explanations. Firstly, our boxers were mostly in the lightweight or middleweight division. Heavyweight boxers hit harder causing more trauma. The fighting distance of our boxers was mostly near or distant. It is known that more eye trauma is encountered in middle distance fighters. In this series, all of our boxers were title holders and therefore had lost relatively few fights (about 16 of 140 bouts).

It is recommended that, before being given a licence to box, amateur and professional boxers should have a complete ophthalmological examination. This examination should be repeated after six bouts, two losses, if eye trauma occurs, and routinely once a year. No fights should be allowed within 30 days of a retinal tear and 60 days of a retinal detachment repair. The minimal requirements for boxing should be a visual acuity of $20 / 40$ or better in each eye and a full central visual field not less than $30^{\circ}$ in each eye. ${ }^{11}$
Take home message

Boxing is potentially dangerous for the eyes. Appropriate protection and periodic check ups are important preventive measures.

\section{Conclusions}

In this series of elite Turkish boxers no serious ophthalmic pathology was encountered. Prospective, longitudinal studies including more boxers of all weight divisions and ages is needed. It can be concluded from this study that boxing is not as hazardous to the eye as previously reported if suitable protective measures such as the use of suitable headgear and gloves are applied. A careful routine ophthalmic examination will reduce the incidence of trauma related vision threatening injuries.

\section{Authors' affiliations}

M Hazar, Gazi University School of Physical Education and Sports, Ankara, Turkey

M Beyleroglu, Sakarya University School of Physical Education and Sports, Turkey

M Subasi, Department of Ophthalmology, Urfa State Hospital, Urfa, Turkey

M Or, Department of Ophthalmology, Gazi University Medical School Ankara

\section{REFERENCES}

1 Sironi VA, Revagnati L. Brain damage in boxers. Lancet 1983;1:244.

2 Jordan BD. Chronic traumatic brain injury associated with boxing. Semin Neurol 2000;20:179-85.

3 Doggart JH. The impact of boxing on the visual apparatus. Arch Ophthalmol 1955;54:161-9.

4 Palmer E, Lieberman TW, Burns S. Contusion angle deformity in prizefighters. Arch Ophthalmol 1976;94:225-8.

5 Whiteson AL. Injuries in professional boxing: their treatment and prevention. Practitioner 1981;225;1053-7.

6 Maguire JL, Bensen WE. Retinal injury and detachment in boxers. JAMA 1986:255:2451-4.

7 Wolter JR. Coup-contrecoup mechanism of ocular injuries. Am J Ophthalmol 1963;56:785-96.

8 Weidenthal DT, Schepens CL. Peripheral fundus changes associated with ocular contusion. Am J Ophthalmol 1966;62:465-77.

9 Wedrich A, Velikay M, Binder S, et al. Ocular findings in asymptomatic amateur boxers. Retina 1993;13:114-19.

10 Kaufman JH, Tolphin DW. Glaucoma after traumatic angle recession. A ten-year prospective study. Am J Ophthalmol 1974;78:648-54.

11 Giovinazzo VJ, Yanuzzi LA, Sorenson JA, et al. The ocular complications of boxing. Ophthalmology 1987;94:587-96.

12 Vadala G, Mollo M, Roberto S, et al. Boxing and the eyes: morphological aspects of the ocular system in boxers. Eur $J$ Ophthalmol 1997;7:174

13 Enzenauer RW, Mauldin WM. Boxing-related ocular injuries in the United States Army, 1980 to 1985. South Med J 1989:82:547-9.

14 National Health and Medical Research Council. Proceedings of the 101 st Session of the National Health and Medical Research Council: the health aspects of boxing. Brisbane: National Health and Medical Research Council, 1986;10:22. 